Article

\title{
Green High-Yielding One-Pot Approach to Biginelli Reaction under Catalyst-Free and Solvent-Free Ball Milling Conditions
}

\author{
Mohamed Ould M'hamed ${ }^{1, *}$, Abdulrahman G. Alshammari ${ }^{1}$ and O. M. Lemine ${ }^{2}$ \\ 1 Department of Chemistry, College of Sciences, Al Imam Mohammad Ibn Saud Islamic University (IMSIU), \\ Riyadh 11623, Saudi Arabia; agshammri@imamu.edu.sa \\ 2 Department of Physics, College of Sciences, Al Imam Mohammad Ibn Saud Islamic University (IMSIU), \\ Riyadh 11623, Saudi Arabia; leminej@yahoo.com \\ * Correspondence: mamhamed@imamu.edu.sa or medabdelwedoud@gmail.com; Tel.: +966-553379046
}

Academic Editor: Rajender S. Varma

Received: 4 November 2016; Accepted: 7 December 2016; Published: 14 December 2016

\begin{abstract}
A simple, green, and efficient approach was used to synthesize 3,4-dihydropyrimidines derivatives. We showed that the application of the planetary ball milling method with a ball-to-reagent weight ratio of 8 for the Biginelli reaction provides 3,4-dihydropyrimidines derivatives with excellent yields $(>98 \%)$ in a short reaction time from the one-pot, three-component condensation of aldehydes, ethyl acetoacetate, and urea (or thiourea).
\end{abstract}

Keywords: Biginelli reaction; ball milling; catalyst-free; solvent-free; dihydropyrimine derivatives

\section{Introduction}

The development of new efficient methods to synthesize organic heterocycles that are both economical and eco-friendly presents a great challenge for the scientific community.

Solvent-free reactions are highly significant from both economical and synthetic points of view. These kinds of reactions ensure an essential facet of green chemistry to reduce the risks to humans and the environment.

Multicomponent reactions (MCRs) have gained importance because of their efficiency and effectiveness as a method for one-pot synthesis of a wide range of heterocycles [1-6]. The optimal MCR is sufficiently flexible. Thus, it can be conducted to generate adducts with a variety of functional groups that may then be selectively paired to enable different cyclization manifolds, thereby leading to a diverse collection of products.

Among the MCRs, the Biginelli reaction [7] is used for the direct synthesis of 3,4-dihydropyrimidine derivatives. The 3,4-dihydropyrimidine and its derivatives are highly significant because they generally show diverse medicinal properties, such as calcium channel blockers, antihypertensive and anti-inflammatory agents, and $\alpha 1$-a antagonists [8-11]. Furthermore, 3,4-dihydropyrimidine derivatives have emerged as important target molecules because of their pharmacological and therapeutic properties, such as antimitotic, antiviral, antitumor, anticarcinogenic, antibacterial, and fungicidal activities [12-19].

Several improvements were made towards good reaction conditions, and they involved the use of catalysts/reagents, transition metal-based reagents, ionic liquids, polymer-immobilized reagents, microwaves, and ultrasound irradiation; these improvements have been recently reported for the synthesis of the aforementioned compounds [20-33].

Despite all of the improved methods, organic synthesis methods still have many drawbacks, such as the use of organic solvents, long reaction times, high costs, low yields, nonsustainable catalysts, and purification issues [34-40]. 
In this study, we propose a new and highly efficient approach to the one-pot synthesis of Biginelli 3,4-dihydropyrimidine derivatives under planetary ball milling solvent-free and catalyst-free conditions (Scheme 1).

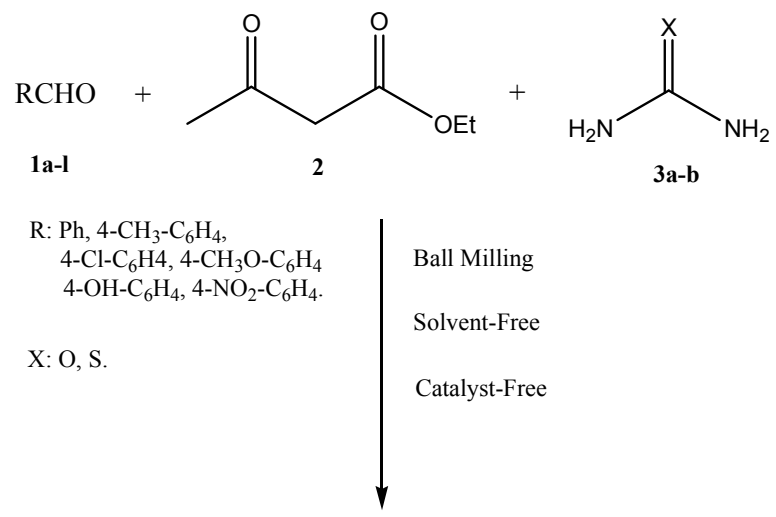<smiles>[X]C1NC(C)=C(C(=O)OCC)C([R])N1</smiles>

Scheme 1. The 3,4-dihydropyrimidine derivatives synthesis under the ball milling technique.

\section{Experimental Section}

\subsection{Materials and Techniques}

The ball mill used in this study was a Planetary Micro Mill PULVERISETTE 7 (Fritsch, Idar-Oberstein, Germany) classic line with $45 \mathrm{~mL}$ tempered steel vials and $10 \mathrm{~mm}$ tempered steel grinding balls. The melting points were determined with a Stuart SMP10 melting point apparatus (Bibby Scientific, Staffordshire, UK). All of the compounds used in this study were purchased from Aldrich (St. Louis, MO, USA). IR spectra were obtained with an FT-IR-Tensor 27 spectrometer in $\mathrm{KBr}$ pellets (Bruker, Ettlingen, Germany). ${ }^{1} \mathrm{H}$ and ${ }^{13} \mathrm{C}-\mathrm{NMR}$ spectra were determined with a Bruker 400 NMR spectrometer (Bruker Biospin, Rheinstetten, Germany) in DMSO- $d_{6}$ with TMS as the internal standard. Chemical shifts were expressed as $\delta$ ppm units. The elemental analysis was performed on a PerkinElmer 2400 CHN Elemental Analyzer (Wellesley, MA, USA). The progress of all reactions was monitored through TLC on silica gel 60 with 1:1 hexane/ethyl acetate.

\subsection{General Procedure for Synthesis of 3,4-Dihydropyrimidine Compound 4a}

An equimolar amount $(0.02 \mathrm{~mol})$ of benzaldehyde (1a), ethyl acetoacetate (2), and urea (3a) (total mass $5.92 \mathrm{~g}$ ) was placed into tempered steel vials with $47.36 \mathrm{~g}$ of tempered steel balls (22 balls of $10 \mathrm{~mm}$ in diameter). The vials were closed and then placed in a Planetary Micro Mill Pulverisette 7, which is set to $750 \mathrm{rpm}$. The 3,4-dihydropyrimidine compound 4 a was obtained in pure form after $30 \mathrm{~min}$ of milling without further purification. 


\section{Results and Discussion}

Recently, Mal et al. [41] showed that the 3,4-dihydropyrimidines can be accessed in two steps under ball milling through a combination of a catalytic amount of potassium bromide ( $\mathrm{KBr})$, oxone and TEMPO (2,2,6,6-Tetramethyl-1-piperidinyloxy).

In this paper, we present an efficient one-pot, three-component solvent-free and catalyst-free approach to synthesize 3,4-dihydropyrimidine derivatives by direct condensation of equimolar quantities of benzaldehyde derivatives, ethyl acetoacetate, and urea/thiourea in a simple planetary ball mill at $750 \mathrm{rpm}$ without adding any solvent or catalyst (Scheme 1). The progress of the reactions was monitored every $10 \mathrm{~min}$ of the milling cycle through thin-layer chromatography (TLC).

We examined different ball ratios (Table 1) to improve the efficiency of the ball milling approach for the Biginelli reaction. Equimolar quantities $(0.02 \mathrm{~mol})$ of benzaldehyde (1a), ethyl acetoacetate (2), and urea (3a) (with a total mass of $5.92 \mathrm{~g}$ ) were introduced in the planetary ball milling, and several milling times and ball weights were tested [42].

Table 1. Milling parameters and the conversion rate for the synthesis of 3,4-dihydropyrimidines derivatives.

\begin{tabular}{cccc}
\hline Entry $^{*}$ & BRR (Balls-to-Reagents Weight Ratio) & Time (min) & Conversion (\%) \\
\hline 1 & $1: 1$ & 720 & 00 \\
2 & $2: 1$ & 720 & 00 \\
3 & $3: 1$ & 720 & 20 \\
4 & $4: 1$ & 720 & 40 \\
5 & $5: 1$ & 300 & 70 \\
6 & $6: 1$ & 360 & 100 \\
7 & $7: 1$ & 180 & 100 \\
8 & $8: 1$ & 30 & 100 \\
\hline
\end{tabular}

* 0.02 mol of benzaldehyde, ethyl acetoacetate, and urea $(5.92 \mathrm{~g})$.

Accordingly, our investigation showed that the reaction does not change even after $12 \mathrm{~h}$ of milling when the ratio (ball weight/reagent weight) is equal to 1 . The increasing value of the ball weight causes the conversion rate to increase to the optimal value for the ball weight-to-reagent weight ratio, which is equal to 8 ( $47.36 \mathrm{~g}$ of balls) (Table 1$)$. The protocol also provides simple access to 3,4-dihydropyrimidine derivatives (4a-j) (Table 2$)$.

This approach exhibits the advantages of high yield, short reaction time (30 min), and easy workup. It is also environmentally benign. All of the synthesized products have been characterized through NMR $\left({ }^{1} \mathrm{H}\right.$ and $\left.{ }^{13} \mathrm{C}\right)$, IR, and elemental analysis.

Table 2. Synthesis of 3,4-dihydropyrimidine derivatives using planetary ball milling technique.

\begin{tabular}{|c|c|c|c|c|c|}
\hline \multirow{2}{*}{ Entry } & \multirow{2}{*}{$\mathbf{R}$} & \multirow{2}{*}{$x$} & \multirow{2}{*}{ Product } & \multirow{2}{*}{ Yield (\%) } & \multirow{2}{*}{$\begin{array}{c}\text { M.P. }\left({ }^{\circ} \mathrm{C}\right) \\
\text { Found Reported References }\end{array}$} \\
\hline & & & & & \\
\hline 1 & $\mathrm{C}_{6} \mathrm{H}_{5-}^{-}$ & $\mathrm{O}$ & $4 a$ & $>98$ & 200-202 (202-204) [40] \\
\hline 2 & $4-\mathrm{CH}_{3}-\mathrm{C}_{6} \mathrm{H}_{4}-$ & $\mathrm{O}$ & $4 b$ & $>98$ & $214-216(215-217)$ [39] \\
\hline 3 & $4-\mathrm{Cl}-\mathrm{C}_{6} \mathrm{H}_{4}-$ & $\mathrm{O}$ & $4 c$ & $>98$ & $208-210(207-210)[40]$ \\
\hline 4 & $4-\mathrm{CH}_{3} \mathrm{O}-\mathrm{C}_{6} \mathrm{H}_{4}-$ & $\mathrm{O}$ & $4 d$ & $>98$ & $204-207$ (203-205) [40] \\
\hline 5 & $4-\mathrm{OH}-\mathrm{C}_{6} \mathrm{H}_{4}-$ & $\mathrm{O}$ & $4 e$ & $>98$ & $221-223(224-227)[40]$ \\
\hline 6 & $4-\mathrm{O}_{2} \mathrm{~N}-\mathrm{C}_{6} \mathrm{H}_{4}-$ & $\mathrm{O}$ & $4 f$ & $>98$ & $208-210(206-208)$ [39] \\
\hline 7 & $\mathrm{C}_{6} \mathrm{H}_{5}-$ & $\mathrm{S}$ & $4 g$ & $>98$ & 209-211 (206-208) [39] \\
\hline 8 & $4-\mathrm{CH}_{3}-\mathrm{C}_{6} \mathrm{H}_{4}-$ & $\mathrm{S}$ & $4 h$ & $>98$ & 187-189 (186-188) [39] \\
\hline 9 & $4-\mathrm{Cl}-\mathrm{C}_{6} \mathrm{H}_{4}-$ & $\mathrm{S}$ & $4 i$ & $>98$ & $182-184(181-183)$ [39] \\
\hline 10 & $4-\mathrm{CH}_{3} \mathrm{O}-\mathrm{C}_{6} \mathrm{H}_{4}-$ & $\mathrm{S}$ & $4 j$ & $>98$ & 155-157 (151-153) [39] \\
\hline 11 & $4-\mathrm{OH}-\mathrm{C}_{6} \mathrm{H}_{4}^{-}$ & $\mathrm{S}$ & $4 k$ & $>98$ & $206-208(200-202)$ [40] \\
\hline 12 & $4-\mathrm{O}_{2} \mathrm{~N}-\mathrm{C}_{6} \mathrm{H}_{4}-$ & $S$ & 41 & $>98$ & 197-199 (191-193) [39] \\
\hline
\end{tabular}




\section{Conclusions}

We developed a simple, green, and quick method for the one-pot Biginelli reaction. This technique is highly efficient. The important advantage of the present procedure, in addition to its simplicity, is its ability to obtain the synthesized 3,4-dihydropyrimidine derivatives in a short reaction time, in pure form, and with excellent yields.

Supplementary Materials: Experimental details and spectroscopic data are available online at www.mdpi.com/ 2076-3417/6/12/431/s1, Figure S1: ${ }^{1} \mathrm{H}-\mathrm{NMR}$ spectrum of compound 4a, Figure S2: ${ }^{13} \mathrm{C}-\mathrm{NMR}$ spectrum of compound 4a, Figure S3: ${ }^{1} \mathrm{H}-\mathrm{NMR}$ spectrum of compound 4g, Figure S4: ${ }^{13} \mathrm{C}-\mathrm{NMR}$ spectrum of compound 4g.

Acknowledgments: The authors extend their appreciation to the Deanship of Academic Research at Al Imam Mohammad Ibn Saud Islamic University (IMSIU), Riyadh, Kingdom of Saudi Arabia, for funding the work through research project Number 341205, $1434 \mathrm{H}$.

Author Contributions: M.O.M. and O.M.L. conceived and designed the experiments; M.O.M. performed the experiments; A.G.A. and O.M.L. analyzed the data; A.G.A. contributed reagents/materials/analysis tools; M.O.M. wrote the paper.

Conflicts of Interest: The authors declare no conflict of interest.

\section{References}

1. Zhu, J.; Bienayme, H. Multicomponent Reactions; Wiley-VCH: Weinheim, Germany, 2005; pp. 33-75.

2. Dömling, A. Recent developments in isocyanide based multicomponent reactions in applied chemistry. Chem. Rev. 2006, 106, 17-89. [CrossRef] [PubMed]

3. Tejedor, D.; Garcia-Tellado, F. Chimo-differentiating ABB' multicomponent reactions. Previleged building blocks. Chem. Soc. Rev. 2007, 36, 484-491. [CrossRef] [PubMed]

4. Müller, T.J.J. Multicomponent reactions. Beilstein J. Org. Chem. 2011, 7, 960-961. [CrossRef] [PubMed]

5. Hernández, J.G.; Turberg, M.; Schiffers, I.; Bolm, C. Mechanochemical strecker reaction: Access to $\alpha$-aminonitriles and tetrahydroisoquinolines under ball-milling conditions. Chem. Eur. J. 2016, 22, 14513-14517. [CrossRef] [PubMed]

6. Polindara-García, L.A.; Juaristi, E. Synthesis of ugi 4-CR and passerini 3-CR adducts under mechanochemical activation. Eur. J. Org. Chem. 2016, 1095-1102. [CrossRef]

7. Biginelli, P. Aldehyde-urea derivatives of aceto-and oxaloacetic acids. Gazz. Chim. Ital. 1893, 23, 360-413.

8. Kidwai, M.; Venkatramanan, R.; Garg, R.K.; Bhushan, K.R. Novel one pot synthesis of new pyranopyrimidines using microwaves. J. Chem. Res(s). 2000, 586-587. [CrossRef]

9. Tabern, D.L.; Volwiler, E.H. Sulfur-containing barbiturate hypnotics. J. Am. Chem. Soc. 1935, 57, 1961-1963. [CrossRef]

10. Atwal, K.S.; Rovnyak, G.C.; O'Reilly, B.C.; Schwartz, J. Substituted1,4-dihydropyrimidines: Synthesis of selectively functionalized 2-hetero-1,4- dihydropyrimidines. J. Org. Chem. 1989, 54, 5898-5907. [CrossRef]

11. Kappe, C.O.; Fabian, W.M.F.; Semones, M.A. Synthetic applications of furan Diels-Alder chemistry. Tetrahedron 1997, 53, 2803-2816.

12. Kappe, C.O. Biologically active dihydropyrimidones of the Biginelli-type-A literature survey. Eur. J. Med. Chem. 2000, 35, 1043-1052. [CrossRef]

13. Mayer, T.U.; Kapoor, T.M.; Haggarty, S.J; King, R.W.; Schreiber, S.I.; Mitchison, T.J. Small molecule inhibitor of mitotic spindle bipolarity identified in a phenotype-based screen. Science 1999, 286, 971-974. [CrossRef] [PubMed]

14. Hurst, E.W.; Hull, R. Two new synthetic substances active against viruses of the psittacosis-lymphogranuloma-trachoma group. J. Med. Pharm. Chem. 1961, 3, 215-229. [CrossRef] [PubMed]

15. Kato, T. Japan Kokai Tokkyo Koho. JP Patent 59,190,974, 1984.

16. Suguira, K.; Schmid, F.A.; Schmid, M.M.; Brown, G.F. Effect of compounds on a spectrum of rat tumors. Cancer Chemother. Rep. Part 2 1973, 3, 231-238.

17. Regnier, G.L.; Canevar, R.J.; Le Douarec, J.C.; Halstop, S.; Daussy, J. Triphenylpropylpiperazine derivatives as new potent analgetic substances. J. Med. Chem. 1972, 15, 295-301. [CrossRef] [PubMed] 
18. Pershin, G.N.; Sherbakova, L.I.; Zykova, T.N.; Sakolova, V.N. Antibacterial activity of pyrimidine and pyrrolo (3,2-d)pyrimidine derivatives. Farmakol. Taksikol. 1972, 35, 466-471.

19. Metolcsy, G. Structure-activity correlations and mode of action of some selected types of antifungal compounds. World Rev. Pest Control 1971, 10, 50-59.

20. Suresh; Sandhu, J.S. Past, present and future of the Biginelli reaction: A critical perspective. ARKIVOV 2012, 66-133.

21. Deyanira, A.-B.; Leticia, L.-R.; Victor, H.L.-C.; Eduardo, G.-Z.; Guillermo, N.-S. Sulfated zirconia-catalyzed synthesis of 3,4-dihydro-pyrimidin-2(1h)-ones (dhpms) under solventless conditions: Competitive multicomponent Biginelli vs. Hantzsch reactions. Molecules 2006, 11, 731-738.

22. Srinivasa, R.J.; Divya, V.; Shubha, J. One-pot three-component biginelli-type reaction to synthesize 5-carboxanilide-dihydropyrimidinones catalyzed by ionic liquids in aqueous media. J. Chem. Tech. Res. 2012, 4, 1720-1727.

23. Gopalakrishnan, A.; Yeon, T.J. A convenient one-pot Biginelli reaction catalyzed by $\mathrm{Y}(\mathrm{OAc})_{3}$ : An improved protocol for the synthesis of 3,4-dihydropyrimidin-2(1h)-ones and their sulfur analogues. Bull. Korean. Chem. Soc. 2010, 31, 863-868.

24. Haline, G.O.; Alvim, T.B.; de Lima, H.C.B.; de Oliveira, F.C.; Gozzo, J.L.; de Macedo, P.V.; Abdelnur, W.A.S.; Brenno, A.D.N. Ionic liquid effect over the biginelli reaction under homogeneous and heterogeneous catalysis. ACS Catal. 2013, 3, 1420-1430.

25. Qu, H.; Li, X.; Mo, F.; Lin, X. Efficient synthesis of dihydropyrimidinones via a three-component Biginelli-type reaction of urea, alkylaldehyde and arylaldehyde. Beilstein J. Org. Chem. 2013, 9, 2846-2851. [CrossRef] [PubMed]

26. Pasunooti, K.K.; Chai, H.; Jensen, C.N.; Gorityala, B.K.; Wang, S.; Liu, X.W. A microwave-assisted, copper-catalyzed three-component synthesis of dihydropyrimidinones under mild conditions. Tetrahedron Lett. 2011, 52, 80-84. [CrossRef]

27. Ding, D.; Zhao, C.G. Primary amine-catalyzed biginelli reaction for the enantioselective synthesis of 3,4-dihydropyrimidin-2(1h)-ones. Eur. J. Org. Chem. 2010, 20, 3802-3805. [CrossRef] [PubMed]

28. Chen, X.H.; Xu, X.Y.; Liu, H.; Cun, L.F.; Gong, L.Z. Highly enantioselective organocatalytic biginelli reaction. J. Am. Chem. Soc. 2006, 128, 14802-14803. [CrossRef] [PubMed]

29. Wang, Y.; Yu, J.; Miao, Z.; Chen, R. Bifunctional primary amine-thiourea-TfOH(BPAT·TfOH) as a chiral phase-transfer catalyst: The asymmetric synthesis of dihydropyrimidines. Org. Biomol. Chem. 2011, 9, 3050-3054. [CrossRef] [PubMed]

30. Murata, H.; Ishitani, H.; Iwamoto, M. Synthesis of Biginelli dihydropyrimidinone derivatives with various substituents on aluminium-planted mesoporous silica catalyst. Org. Biomol. Chem. 2010, 8, 1202-1211. [CrossRef] [PubMed]

31. Ranu, B.C.; Hajra, A.; Jana, U. Indium(III) chloride-catalyzed one-pot synthesis of dihydropyrimidinones by a three-component coupling of 1,3-dicarbonyl compounds, aldehydes, and urea: An improved procedure for the Biginelli reaction. J. Org. Chem. 2000, 65, 6270-6272. [CrossRef] [PubMed]

32. Ma, Y.; Qian, C.; Wang, L.; Yang, M. Lanthanide triflate catalyzed Biginelli reaction. one-pot synthesis of dihydropyrimidinones under solvent-free conditions. J. Org. Chem. 2000, 65, 3864-3868. [CrossRef] [PubMed]

33. Lu, J.; Ma, H. Iron(III)-catalyzed synthesis of dihydropyrimidinones. Improved conditions for the Biginelli reaction. Synlett 2000, 1, 63-64.

34. Litvic, M.; Vecenaj, I.; Ladisic, Z.M.; Lovric, M.; Vinkovic, V.; Filipan-Litvic, M. First application of hexaaquaaluminium(III) tetrafluoroborate as a mild, recyclable, non-hygroscopic acid catalyst in organic synthesis: A simple and efficient protocol for the multigram scale synthesis of 3,4-dihydropyrimidinones by Biginelli reaction. Tetrahedron 2010, 66, 3463-3471. [CrossRef]

35. Dharma Rao, G.B.; Acharya, B.N.; Verma, S.K.; Kaushik, M.P. N,N'-Dichlorobis(2,4,6-trichlorophenyl)urea (CC-2) as a new reagent for the synthesis of pyrimidone and pyrimidine derivatives via Biginelli reaction. Tetrahedron Lett. 2011, 52, 809-812.

36. Narahari, S.R.; Reguri, B.R.; Gudaparthi, O.; Mukkanti, K. Synthesis of dihydropyrimidinones via Biginelli multi-component reaction. Tetrahedron Lett. 2012, 53, 1543-1545. [CrossRef] 
37. Konkala, K.; Sabbavarapu, N.M.; Katla, R.; Durga, N.Y.V.; Reddy, T.V.K.; Devi, B.; Prasad, R.B.N. Revisit to the Biginelli reaction: A novel and recyclable bioglycerol-based sulfonic acid functionalized carbon catalyst for one-pot synthesis of substituted 3,4-dihydropyrimidin-2-(1H)-ones. Tetrahedron Lett. 2012, 53, 1968-1973. [CrossRef]

38. Da Silva, D.L.; Fernandes, S.A.; Sabino, A.A.; de Fatima, A. $p$-Sulfonic acid calixarenes as efficient and reusable organocatalysts for the synthesis of 3,4-dihydropyrimidin-2(1H)-ones/-thiones. Tetrahedron Lett. 2011, 52, 6328-6330. [CrossRef]

39. Javad, S.G.; Raheleh, T.; Abolfazl, Z. A green synthesis of 3,4-dihydropyrimidine-2(1H)-one/thione derivatives using nanosilica-supported tin(II) chloride as a heterogeneous nanocatalyst. Monatsh. Chem. 2013, 144, 1865-1870.

40. Zhang, Y.; Wang, B.; Zhang, X.; Huang, J.; Liu, C. An efficient synthesis of 3,4-dihydropyrimidin-2(1H)-ones and thiones catalyzed by a novel brønsted acidic ionic liquid under solvent-free conditions. Molecules 2015, 20, 3811-3820. [CrossRef] [PubMed]

41. Sahoo, P.K.; Bose, A.; Mal, P. Solvent-free ball-milling Biginelli reaction by subcomponent synthesis. Eur. J. Org. Chem. 2015, 32, 6994-6998. [CrossRef]

42. Ould M'hamed, M.; Alduaij, O.K. An efficient one-pot synthesis of new 2-thioxo and 2-oxo-pyrimidine-5-carbonitriles in ball-milling under solvent-free and catalyst-free conditions. Phosphorus Sulfur Silicon Relat. Elem. 2014, 189, 235-241. [CrossRef]

(C) 2016 by the authors; licensee MDPI, Basel, Switzerland. This article is an open access article distributed under the terms and conditions of the Creative Commons Attribution (CC-BY) license (http:/ / creativecommons.org/licenses/by/4.0/). 